\title{
Prevalence, predictors, and mortality of bloodstream infections due to methicillin- resistant Staphylococcus aureus in patients with malignancy: systemic review and meta-analysis
}

\author{
Zhouqi $\mathrm{Li}^{1 \dagger}$, Hemu Zhuang ${ }^{2+}$, Guannan Wang ${ }^{3}$, Hui Wang ${ }^{1}$ and Ying Dong ${ }^{1 *}$
}

\begin{abstract}
Background: Cancer patients are more likely to develop and die of bloodstream infection (BSI) than noncancer patients. Methicillin-resistant Staphylococcus aureus (MRSA), which is associated with immense mortality and economic burden worldwide, is not covered by the recommended initial antibiotic therapy for cancer patients with BSI. This systemic review was performed to estimate the global methicillin-resistant Staphylococcus aureus (MRSA) prevalence among bacteremia in patients with malignancy, and further study the predictors and mortality of cancer patients with MRSA bacteremia.

Methods: The PubMed and EMBASE databases were searched for studies published from Jan. 2000 to Mar. 2020 that provided primary data on the prevalence, predictors, or mortality of MRSA bacteremia in cancer patients. A random-effects model meta-analysis was performed to estimate the pooled prevalence of MRSA with 95\% confidence intervals (95\% Cls).

Results: The pooled prevalence of MRSA was 3\% (95\% Cl 2-5\%) among all bloodstream infections (BSIs) and 44\% (95\% Cl 32-57\%) among S. aureus bacteremia in cancer patients. Based on geographical stratification, the pooled prevalence was $5 \%$ in Africa (95\% Cl 1-14\%), 1\% in Americas (95\% Cl 1-2\%), 2\% in Europe (95\% Cl 1-4\%), 4\% in Western Pacific (95\% Cl 2-7\%), 8\% in South-east Asia (95\% Cl 4-14\%) and 0\% in Eastern Mediterranean (95\% Cl 0-3\%). No significant temporal change in MRSA rates was detected in this analysis $\left(R^{2}=0.06 ; P=0.24\right)$. Predictors for MRSA BSIs among cancer patients were identified by comparison with their methicillin-susceptible counterparts, and they were mainly related to healthcare-associated infections and immunosuppression. Finally, the 60-day mortality in adult cancer patients with MRSA BSIs was reported to be $12 \%$, and the 6 -month overall mortality was $43.2 \%$, with community-onset infection, secondary BSI, and vancomycin MIC $\geq 2 \mathrm{~g} / \mathrm{mL}$ being the risk factors for mortality.

(Continued on next page)
\end{abstract}

\footnotetext{
* Correspondence: dongying74@zju.edu.cn

†Z Zhouqi Li and Hemu Zhuang contributed equally to this work.

'Department of Medical Oncology, The Second Affiliated Hospital, College of Medicine, Zhejiang University, Hangzhou, Zhejiang, China

Full list of author information is available at the end of the article
}

C C The Author(s). 2021 Open Access This article is licensed under a Creative Commons Attribution 4.0 International License, which permits use, sharing, adaptation, distribution and reproduction in any medium or format, as long as you give appropriate credit to the original author(s) and the source, provide a link to the Creative Commons licence, and indicate if changes were made. The images or other third party material in this article are included in the article's Creative Commons licence, unless indicated otherwise in a credit line to the material. If material is not included in the article's Creative Commons licence and your intended use is not permitted by statutory regulation or exceeds the permitted use, you will need to obtain permission directly from the copyright holder. To view a copy of this licence, visit http://creativecommons.org/licenses/by/4.0/ The Creative Commons Public Domain Dedication waiver (http://creativecommons.org/publicdomain/zero/1.0/) applies to the data made available in this article, unless otherwise stated in a credit line to the data. 
(Continued from previous page)

Conclusions: Although the prevalence of MRSA BSIs among cancer patients is relatively low, it did not decline over time as MRSA BSIs in the general hospital population and the high mortality rate was related to MRSA BSIs in patients with malignancy.

Keywords: Methicillin-resistant Staphylococcus aureus, MRSA, Bacteremia, Cancer, Prevalence

\section{Background}

Cancer patients are highly susceptible to bloodstream infection (BSI) due to frequent hospital admissions, cytotoxic chemotherapy, use of invasive procedures, and exposure to broad-spectrum antibiotics [1, 2]. Accordingly, they witnessed a more significant increase in the incidence of BSI, and a higher mortality rate than noncancer patients in recent years [3], with prevalence ranging from 11 to $38 \%$ and the mortality rate around $40 \%$ [4]. In a study investigating nearly 14 million patients with BSI in the US from 2006 to 2014, Gram-positive bacteria are found to be the leading causative pathogens $(27.38 \%)$ in cancer patients [3]. despite a shift from Gram-positive to Gram-negative organisms has been documented in recent years [5].

Staphylococcus aureus, a common Gram-positive bacterium colonizing the skin, the nares, and the perineum, frequently causes skin, soft tissue, and bloodstream infections in human beings [6]. S. aureus Bacteremia (SAB) is one of the most serious situations in $S$. aureus infections and is related to mortality rates of $15-60 \%$ [7, 8]. Underlying malignancy has been reported to be a risk factor for mortality in patients with $S A B$ in several studies [9-12]. In turn, the presence of SAB also indicated an increased risk of death in cancer patients [13, 14].

$S$. aureus is known to be frequently antibiotic-resistant, and methicillin-resistant $S$. aureus (MRSA) infections have been the main cause of mortality and the immense economic burden attributed to $S$. aureus infections worldwide $[15,16]$. Methicillin-resistance adversely affected the outcome of patients with $\mathrm{SAB}$ whether in the general population or cancer patients $[9,14,17-19]$, and appropriate empirical antibiotic treatment significantly improved the outcome [20]. The recommended first-line therapy for MRSA bacteremia is appropriately dosed vancomycin, with daptomycin an effective alternative [21]. However, the NCCN Guidelines strongly recommended vancomycin not be routinely included in the empiric therapy alone for cancer patients [22], which could impair the prognosis of patients with MRSA BSI. Thus, there is an urgent need for data on the prevalence, and the risk factors for the development and mortality of MRSA BSIs in cancer patients for better management of MRSA in this population. In this systemic review, we performed a meta-analysis on the global MRSA prevalence among bacteremia in patients with malignancy and further summarized the limited information on the predictors and mortality of cancer patients with MRSA BSI.

\section{Methods}

This study was conducted and reported based on the Preferred Reporting Items for Systematic Reviews and Meta-Analyses (PRISMA) guidelines [23].

\section{Literature search}

We searched the PubMed and EMBASE databases for studies published up to 11 Mar 2020. The search strategy consisted of \#1 (tumor* OR tumour* OR cancer* OR carcinoma* OR malignanc* OR neoplasia* OR oncolog* OR sarcoma* OR hematolog* OR haematolog* OR leukemia* OR leukaemia* OR lymphoma"), \#2 ("bloodstream infection" OR "blood stream infection"” OR bacteremia OR bacteraemia), \#3 ("Methicillin-Resistant Staphylococcus aureus" OR MRSA OR "Staphylococcus aureus" OR "S. aureus"). The search was conducted as \#1 AND \#2 AND \#3 limited to the title and abstract with the filters: human, English, and recent 20 years. Additional articles were identified by manually searching reference lists of the identified articles and relevant reviews [24, 25]. Further articles citing the included studies were retrieved using Web of Science.

\section{Study selection}

Studies were included if they met either inclusion criterion, and did not meet any of the exclusion criteria. The inclusion criteria were: 1 . studies containing primary data on the total number of blood isolates from BSI cases and the number of MRSA isolates in 10 or more cancer patients; 2 . studies that provided data on the predictors or mortality of cancer patients with MRSA BSI. The exclusion criteria were: 1 . no differentiation between laboratory-confirmed infections and contamination; 2. studies that focused on microbial isolates with no relation to clinical BSI cases; 3 . MRSA outbreak; 4. non-English publications; 5. not available in full-text, including conference abstracts. Title and abstract screening and full-text assessment were conducted independently by two authors after duplicates were removed, with discrepancies resolved by consensus.

\section{Data extraction and quality assessment}

Data collected included study characteristics (primary author, year of publication, country, study design, study 
period, and study setting), prevalence (the total number of BSI isolates and the number of isolates of Gram-positive bacteria, $S$. aureus, and MRSA). The total number of microbial isolates from cancer patients with BSI was collected to calculate the prevalence of MRSA, because the number of patients, as well as the BSI episodes, was not available in all studies. MRSA rates in S. aureus were calculated in a study when the number of $S$. aureus was more than 10 . Furthermore, demographic and clinical factors associated with MRSA predictors and mortality, as well as the mortality rate of patients with MRSA BSIs, were collected.

The methodological quality of all identified studies was evaluated by the Newcastle-Ottawa scale [26]. Based on this scale, studies received stars across three categories: selection and comparability of study groups, and outcome ascertainment. Generally, the rating criteria were: Low quality $=0-5$; medium quality $=6-7$; and high quality $=8-$ 9. The studies on prevalence could score five stars at most and were considered of high quality with four or five stars [24], because the non-exposed cohort and the outcome at the beginning were not applicable to these studies.

\section{Statistical analysis}

A random-effects meta-analysis was performed to estimate the pooled prevalence of MRSA with $95 \%$ confidence intervals (95\% CIs) [27]. World Health Organization (WHO) geographical stratification was applied to study the geographic variation of MRSA prevalence. Temporal trends in MRSA prevalence was assessed by linear regression. The proportions of MRSA isolates in two subgroups were compared with Chi-square test. The meta-analysis, linear regression, and Chi-square test were conducted by MedCalc statistical software, version 15.2 (MedCalc Software, Ostend, Belgium). Publication bias was tested by funnel plot and Egger's test, and the data were analyzed by the statistical software R (Version 3.6.3, R Foundation for Statistical Computing, Vienna, Austria) with the meta package (Version 4.11-0). Rates in each study were stabilized using the Freeman-Tukey double-arcsine transformation before analysis to minimize the effect of extremely small rates [28]. Study heterogeneity was assessed with the $\mathrm{I}^{2}$ test and interpreted as relevant if $>50 \%$. Generally, a $P$-value of $<0.05$ was considered statistically significant, but statistically significant publication bias was suggested when $P$-value was less than 0.1 on Egger's test.

\section{Results}

\section{Search results, quality assessment, and studies characteristics}

As shown in Fig. 1, a total of 831 articles were retrieved from PubMed and EMBASE together with additional sources. 577 records were screened by title and abstract following the removal of duplicates, and 429 articles were crossed out. After a full-text review of the remaining
148 articles, 121 articles were excluded. Finally, 27 studies were considered eligible, with 24 included in the metaanalysis for MRSA prevalence [5, 13, 29-50], three in the potential MRSA predictors $[13,51,52]$, and two in the risk factors for mortality in patients with MRSA BSIs [53]. The selected studies scored five or six according to the Newcastle-Ottawa scale and were considered of high or moderate quality (Supplementary Table S1).

The characteristics of the studies concerning MRSA prevalence are shown in Table 1 . The studies collected BSI data in cancer patients between 1995 and 2017 and were from 19 countries covering all the six WHO geographical stratifications. All studies were observational; 12 were retrospective cohorts, 10 were prospective cohorts, and two were cross-sectional studies. Most of the studies were single-center studies except for two multicenter studies. More than half of the studies included only adults with a proportion of males varying between 39.7 and $69.9 \%$. In total, 10,550 BSI isolates were included in the meta-analysis for MRSA prevalence. The characteristics of the studies included in the analysis of MRSA predictors and mortality were summarized in Supplementary Table S2.

\section{Prevalence of MRSA-BSIs}

Overall, the 24 data sets presented a pooled MRSA rate of $3 \%\left(95 \%\right.$ CI 2-5\%) (Fig. 2). High heterogeneity $\left(\mathrm{I}^{2}=91 \%\right)$ was present among the studies. The funnel plot seemed approximately symmetrical (Supplementary Fig. S1) and no significant publication bias was detected by further Egger's test $(p=0.12)$.

Among a subset of 23 studies that contained data on 3690 Gram-positive BSI cases, the MRSA isolation rate in Gram-positive bacteria was $10 \%$ (95\% CI 6-14\%) $[5,13,29-46,48-50]$. In 15 studies whose number of $S$. aureus was more than 10, the pooled prevalence of MRSA among S. aureus was 44\% (95\% CI 32-57\%) [5, 13, 29, 33, 35, 37, 39, 42-49].

Subgroup analyses of MRSA prevalence were conducted by region, age group, type of cancer, and the presence of febrile neutropenia. The prevalence of MRSA was 5\% in Africa (95\% CI $1-14 \%), 1 \%$ in Americas (95\% CI 1-2\%), $2 \%$ in Europe (95\% CI 1-4\%), 4\% in Western Pacific (95\% CI 2-7\%), 8\% in South-east Asia (95\% CI 4-14\%) and 0\% in Eastern Mediterranean (95\% CI 0-3\%). All 6 regions showed significantly different MRSA rates when compared to the rest of the regions (all $P<0.05$ ). Ghana, an African country, saw the greatest MRSA rate $(28 \%)$ which was nearly 10 times higher than the overall prevalence [49]. On the contrary, four studies from different regions (Africa, Europe, Western Pacific, and Eastern Mediterranean) did not detect MRSA in BSI cases [32, 34, 41, 50]. In addition, studies demonstrate no statistically significant changes 


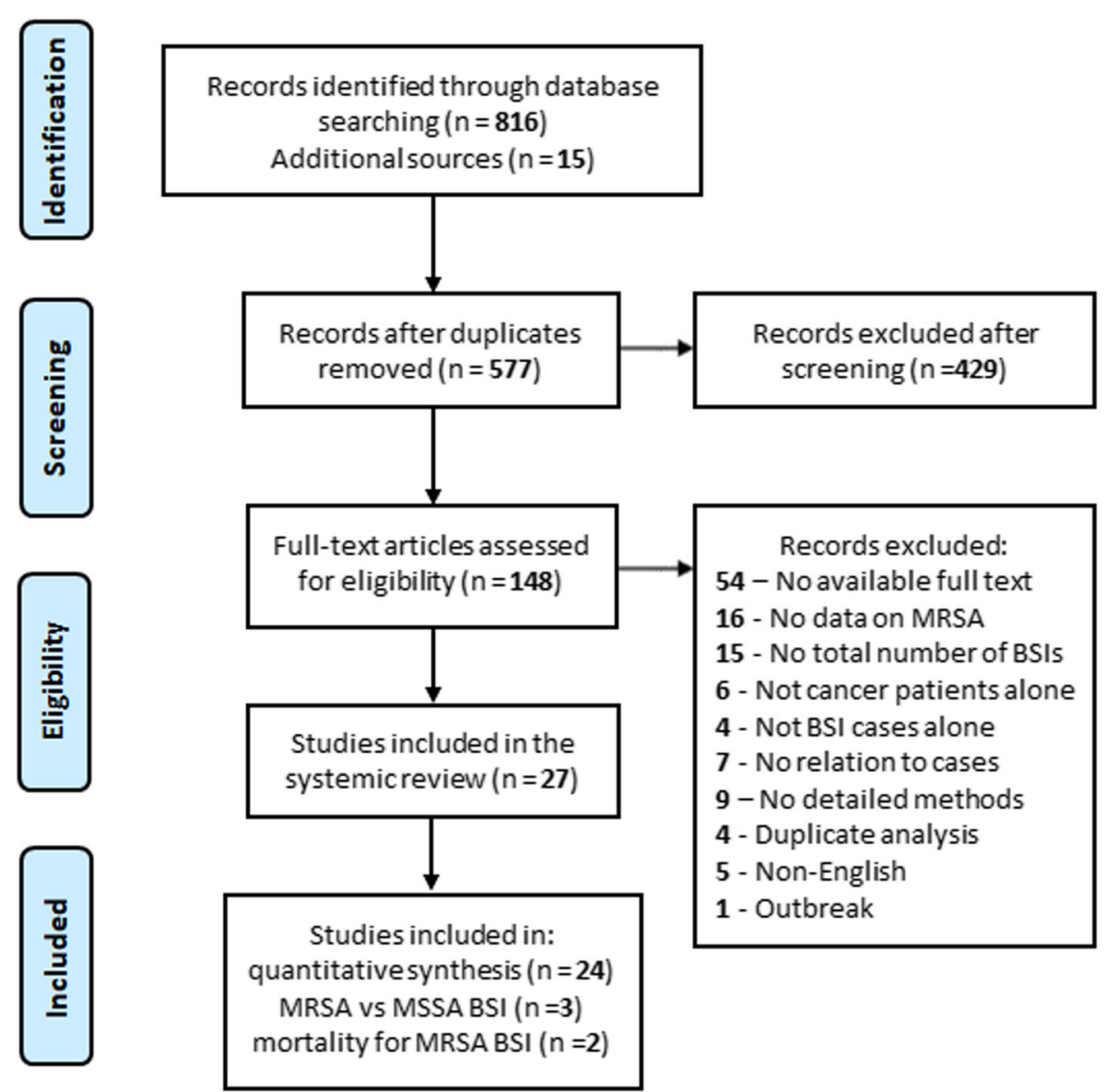

Fig. 1 Flow chart of study selection. MRSA, methicillin-resistant Staphylococcus aureus; MSSA, methicillin-susceptible Staphylococcus aureus; BSI, bloodstream infection

through the examination of the temporal trend of the MRSA prevalence rates $\left(R^{2}=0.06 ; P=0.24\right)$ (Fig. 3).

Based on data from 16 studies on 8461 adult BSI isolates, the MRSA isolation rate among BSIs in adults was $4 \%(95 \%$ CI 3-6\%) [5, 13, 29, 32, 33, 36, 37, 39, 40, 42, 44-49]. Besides, five studies reported data on 927 BSI isolates from children and the MRSA prevalence in this population was $2 \%(95 \%$ CI $0-5 \%)$ [31, 34, 38, 43, 50]. When comparing the two groups, the difference in the MRSA rates was statistically significant $\left(\chi^{2}=12.7 ; P=\right.$ 0.0004).

To discriminate the MRSA prevalence in BSI cases with hematological malignancy and solid tumors, a Spanish study [54] which was previously excluded for duplicate analysis was retrieved and included in the latter group. In this way, 685 BSI cases among patients with solid tumors from two studies were identified, and the prevalence of MRSA in this subgroup was $4 \%$ (95\% CI $0-12 \%$ ) [42, 54]. Seven studies provided data on 3569 BSI isolates from patients with hematological malignancies and the pooled prevalence of MRSA was $4 \%(95 \%$
CI 1-7\%) [32, 33, 39, 40, 44-46]. The difference between the two groups did not reach statistical significance $\left(x^{2}=0.03 ; P=0.86\right)$.

In the specific subgroup of patients with febrile neutropenia, a total of 1351 BSI isolates from eight studies saw a pooled MRSA rate of $2 \%$ (95\% CI 1-5\%) [31, 32, $34,36,37,40,46,50]$. Half of the studies were conducted in Europe [34, 36, 40, 46], two studies in the Western Pacific [31, 32], one in South-East Asia [37], and one in the Eastern Mediterranean [50].

\section{Predictors for MRSA-BSIs}

Risk factors for the development of MRSA bacteremia among cancer patients with BSIs were summarized in Table 2. All the three relevant studies $[13,51,52]$ compared the demographic and clinical characteristics of cancer patients with MRSA BSIs to their counterparts with methicillin-susceptible $S$. aureus (MSSA) BSIs. Hospital-acquired BSI was found to be more prevalent during MRSA BSIs than MSSA BSIs in two studies, although with slightly different definitions [13, 52]. 
Table 1 Characteristics of the included studies on MRSA prevalence

\begin{tabular}{|c|c|c|c|c|c|c|c|}
\hline Region/Study & Country & $\begin{array}{l}\text { Study } \\
\text { perioid }\end{array}$ & Setting & $\begin{array}{l}\text { No. of BSI } \\
\text { isolates }\end{array}$ & $\begin{array}{l}\text { No. of GP } \\
\text { bacteria (\%) }\end{array}$ & $\begin{array}{l}\text { No. of } \\
\text { MRSA (\%) }\end{array}$ & $\begin{array}{l}\text { MRSA rates } \\
\text { in S. aureus } \\
\end{array}$ \\
\hline \multicolumn{8}{|l|}{ Africa } \\
\hline El-Mahallawy et al. 2005 [43] & Egypt & 1999 & Children with ST or HM & 328 & $168(51.2)$ & $18(5.5)$ & $40.9 \%$ \\
\hline Arega et al. 2018 [49] & Ethiopia & 2011-2012 & Adults with ST or HM & 82 & $43(52.4)$ & $23(28.0)$ & $74.2 \%$ \\
\hline Obeng-Nkrumah et al. 2015 [41] & Ghana & 2010-2013 & $\begin{array}{l}\text { Adults and children with } \\
\text { ST or HM }\end{array}$ & 93 & $40(43.0)$ & $0(0.0)$ & NA \\
\hline Mvalo et al. 2018 [38] & South Africa & 2012-2014 & Children with ST or HM & 173 & $85(49.1)$ & $2(1.2)$ & NA \\
\hline Lubwama et al. 2019 [30] & Uganda & 2014 & $\begin{array}{l}\text { Adults and children with } \\
\text { ST or HM }\end{array}$ & 33 & $11(33.3)$ & $1(3.0)$ & NA \\
\hline \multicolumn{8}{|l|}{ Americas } \\
\hline Velasco et al. 2004 [35] & Brazil & 2000-2002 & $\begin{array}{l}\text { Adults and children with } \\
\text { ST or HM }\end{array}$ & 1036 & $328(31.7)$ & $17(1.6)$ & $18.7 \%$ \\
\hline Islas-Munoz et al. 2018 [5] & Mexico & 2016-2017 & Adults with ST or HM & 496 & $135(27.2)$ & $4(0.8)$ & $8.0 \%$ \\
\hline \multicolumn{8}{|l|}{ Europe } \\
\hline Anatoliotaki et al. 2004 [42] & Greece & 1995-2000 & Adults with ST & 157 & $54(34.4)$ & $12(7.6)$ & $85.7 \%$ \\
\hline Schelenz et al. 2013 [48] & UK & 1997-2010 & Adults with ST or HM & 949 & $560(59.0)$ & $26(2.7)$ & $32.1 \%$ \\
\hline Miedema et al. 2013 [34] & $\begin{array}{l}\text { Netherlands; } \\
\text { Switzerland }\end{array}$ & 2004-2011 & $\begin{array}{l}\text { Children with ST or HM } \\
\text { and FN }\end{array}$ & 248 & $180(72.6)$ & $0(0.0)$ & NA \\
\hline Horasan et al. 2011 [36] & Turkey & 2004-2009 & $\begin{array}{l}\text { Adults with ST or HM } \\
\text { and FN }\end{array}$ & 98 & $47(48.0)$ & $3(3.1)$ & NA \\
\hline Kara et al. 2015 [46] & Turkey & 2005-2009 & Adults with $\mathrm{HM}$ and $\mathrm{FN}$ & 536 & $192(35.8)$ & $7(1.3)$ & $23.3 \%$ \\
\hline Bodro et al. 2014 [47] & Spain & $2006-2011$ & Adults with ST or HM & 1148 & NA & $13(1.1)$ & $12.3 \%$ \\
\hline Gedik et al. 2014 [40] & Turkey & 2010-2012 & Adults with $\mathrm{HM}$ and FN & 90 & $17(18.9)$ & $4(4.4)$ & NA \\
\hline \multicolumn{8}{|l|}{ Western Pacific } \\
\hline Lai et al. 2003 [31] & Taiwan, China & 1999 & $\begin{array}{l}\text { Children with ST or HM } \\
\text { and FN }\end{array}$ & 46 & $11(23.9)$ & $3(6.5)$ & NA \\
\hline Wang et al. 2005 [33] & Taiwan, China & 1999-2002 & Adults with HM & 418 & 87 (20.8) & $39(9.3)$ & $73.6 \%$ \\
\hline Huang et al. 2011 [29] & Taiwan, China & 2003-2005 & Adults with ST or HM & 588 & $153(26.0)$ & $24(4.1)$ & $55.8 \%$ \\
\hline Baskaran et al. 2007 [32] & Malaysia & 2004-2005 & Adults with $\mathrm{HM}$ and FN & 73 & $29(39.7)$ & $0(0.0)$ & NA \\
\hline Yamamoto et al. 2010 [39] & Japan & 2003-2007 & Adults with HM & 119 & 89 (74.8) & $14(11.8)$ & $82.4 \%$ \\
\hline Kang et al. 2012 [13] & South Korea & $\begin{array}{l}2006-2007 ; \\
2008-2009\end{array}$ & Adults with ST or HM & 1246 & $408(32.7)$ & $59(4.7)$ & $48.4 \%$ \\
\hline Kwon et al. 2013 [45] & South Korea & 2009-2010 & Adults with HM & 243 & $122(50.2)$ & $7(2.9)$ & $63.6 \%$ \\
\hline Chen et al. 2017 [44] & Taiwan, China & 2008-2013 & Adults with HM & 2090 & $841(40.2)$ & $24(1.1)$ & $42.1 \%$ \\
\hline \multicolumn{8}{|l|}{ South-east Asia } \\
\hline Bhat et al. 2016 [37] & India & 2012-2014 & $\begin{array}{l}\text { Adults with ST or HM } \\
\text { and FN }\end{array}$ & 128 & $51(39.8)$ & $10(7.8)$ & $31.3 \%$ \\
\hline \multicolumn{8}{|l|}{ Eastern Mediterranean } \\
\hline Greenberg et al. 2005 [50] & Israel & 1998-2002 & $\begin{array}{l}\text { Children with ST or HM } \\
\text { and FN }\end{array}$ & 132 & $39(29.5)$ & $0(0.0)$ & NA \\
\hline
\end{tabular}

BSI bloodstream infection, GP Gram-positive, MRSA methicillin-resistant Staphylococcus aureus, ST solid tumors, HM hematological malignancy, FN febrile neutropenia, NA not applicable

Consistently, Indwelling urinary catheter, the presence of nasogastric tube, the need for catheter removal, and healthcare-associated pneumonia as origin were shown to be related to a higher possibility for MRSA development [13, 51]. In the specific population with hematologic malignancies, hospital-acquired infection was also identified as a predisposing factor for MRSA, and primary bacteremia was found to be a protective factor [52].

\section{Mortality of MRSA-BSIs}

The 60-day mortality in adult cancer patients with MRSA BSIs was reported to be $12 \%$ [53], and the 6month overall mortality was $43.2 \%$ [52]. In those who 


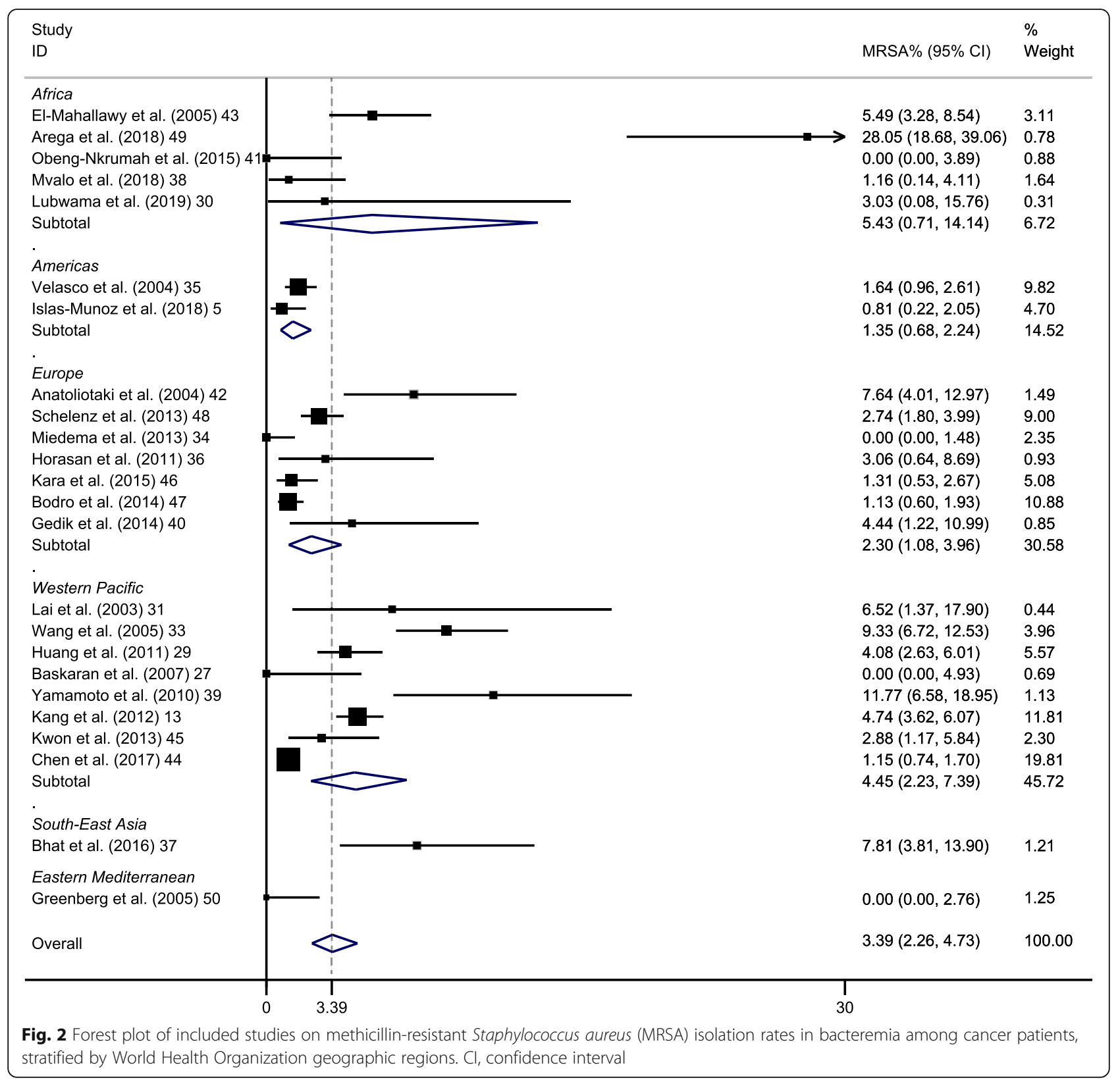

were treated with vancomycin, the treatment failure rate was $52 \%$ with the failure defined as death, uncontrolled infection, rapid relapse, or severe adverse events [53]. Concerning the risk factors for mortality in cancer patients with MRSA BSIs, multivariate analysis revealed that community-onset infection, secondary BSI, and vancomycin $\mathrm{MIC} \geq 2 \mathrm{~g} / \mathrm{mL}$ were significantly related to 60-day mortality [53].

\section{Discussion}

S. aureus is one of the 'ESKAPE' organisms that are responsible for the majority of bacterial infections in patients with malignancy [55]. Besides, bacteremia and multi-drug resistance has become a growing issue in cancer patients [4]. In our study, MRSA is the causative pathogen in $3 \%$ of BSIs among patients with malignancy in general. This rate can be as high as $28 \%$ in an African country, rendering Africa being the second-highest region considering MRSA rates. However, three in five African countries had MRSA rates lower than the global pooled prevalence, indicating high heterogeneity among different regions. Statistically, high heterogeneity was present in each subgroup. Thus, The treatment of BSIs in patients with cancer should take the local microbiology and antibiotic-sensitivity patterns into account, besides referring to the established guidelines [56]. It is notable that limited information is available in the literature on MRSA BSIs in South-East Asia, Eastern Mediterranean, 


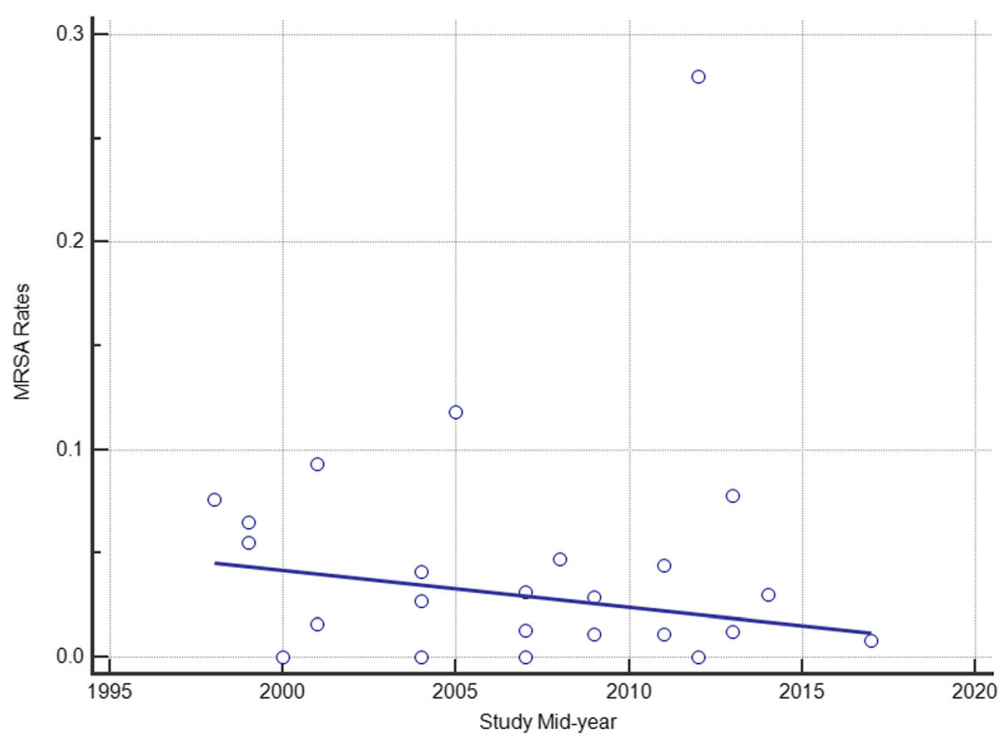

Fig. 3 Temporal trends of MRSA isolation rates in bacteremia among cancer patients. Circles represent the prevalence from the included study and the regression line is shown by study mid-year

and Americas, suggesting the need for further studies of high quality in these regions to better understand the overall burden of MRSA BSIs in cancer patients.

In recent years, a variety of effective measures, including improvements in preventing healthcare-associated infections and MRSA transmission interruption in hospitals, were taken to control infections [57]. As a result, hospital-onset MRSA bacteremia rates substantially reduced between 2005 and 2012, and the rate of decrease has slowed since 2012 in the general population of the US [57]. However, this decline was not detected in MRSA-BSIs among patients with malignancy, which might be explained by two possible reasons: firstly, although with the emergence of colony-stimulating factors, Immunomodulatory drugs, etc., cancer patients are still exposed to cytotoxic chemotherapy, broad-spectrum antibiotics, and undergo frequent invasive procedures, rendering them immunosuppressed and susceptible to MRSA; secondly, the rate of community-associated MRSA (CA-MRSA) remains stable, and there is a surge of MRSA in some regions [16, 57]. CA-MRSA, unlike hospital-acquired MRSA which could be effectively controlled by vigorous hand hygiene, antimicrobial stewardship, and barrier precautions, lacks easily targeted prevention strategies [58]. Strains of CA-MRSA are more likely to spread in densely populated regions, and therefore might be controlled by constant surveillance and early intervention [58]. This could also partly explain the relatively high rate of MRSA in Western Pacific and South-east Asia in our analysis.

MRSA BSI predictors among cancer patients were reported in three studies. All of the studies compared MRSA to MSSA, but each study contained different clinical factors, which precluded a pooled analysis. The

Table 2 Predictors for BSI due to MRSA in cancer patients

\begin{tabular}{|c|c|c|c|c|c|}
\hline Study & Type of analysis & Predictor & Prevalence (\%) & OR $(95 \% \mathrm{Cl})$ & $\mathbf{P}$ \\
\hline \multirow[t]{3}{*}{ Bello-Chavolla et al. 2018 [52] } & Multivariate analysis & Hospital-acquired infection & $56(58.9)$ & $5.54(3.27-9.38)$ & $<0.001$ \\
\hline & & Healthcare-associated pneumonia & $19(20.0)$ & $3.02(1.63-5.59)$ & $<0.001$ \\
\hline & & Diabetes mellitus & $67(18.9)$ & $2.09(1.02-4.28)$ & 0.049 \\
\hline \multirow[t]{4}{*}{ Kang et al. 2012 [13] } & Univariate analysis & Nosocomial acquisition & $45(76.3)$ & $3.11(1.43-6.77)$ & 0.004 \\
\hline & & Indwelling urinary catheter & $25(42.4)$ & $3.90(1.67-9.12)$ & 0.001 \\
\hline & & Nasogastric tube & $12(20.3)$ & $5.11(1.36-19.14)$ & 0.009 \\
\hline & & ICU admission & $17(28.8)$ & $4.70(1.61-13.73)$ & 0.003 \\
\hline \multirow[t]{2}{*}{ Srinivasan et al. 2010 [51] } & Chi-square test & Persistently positive blood cultures & $5(50)$ & & 0.004 \\
\hline & & Catheter removal & $6(60)$ & & 0.003 \\
\hline
\end{tabular}


identified predictors were mainly related to healthcareassociated infections and immunosuppression. In a study exploring MRSA BSI predictors in HIV-infected patients, multivariate analysis revealed that frequent hospitalization, low numbers of $\mathrm{CD} 4+$ peripheral cells, and previous administration of beta-lactams were found to be independent risk factors of MRSA development [59], which is partly in line with the findings in cancer patients. Prior antibiotic use was identified as the only independent predictor of MRSA bacteremia after analysis of data from two prospective multi-center studies in the general population [60]. Unfortunately, this clinical event frequently experienced by cancer patients was not studied in our included studies. Further studies comparing MRSA BSIs with allcause BSIs and involving more demographic and clinical factors are needed to establish a reliable prediction rule for MRSA BSIs in the cancer population.

As reported in the previous researches, the 30-day mortality of MRSA BSIs ranged from 16 to $44 \%$ in general hospital populations [11, 20, 61-63]. This mortality was attributed to multiple complications of MRSA bacteremia, including infective endocarditis, deep tissue abscess, and septic shock [64]. However, data on the mortality rate of MRSA-BSIs in cancer patients is scarce, and hard to make a comparison. When it comes to the risk factors for mortality among patients with MRSA bacteremia, community-onset infection, secondary BSI, and vancomycin $\mathrm{MIC} \geq 2 \mathrm{~g} / \mathrm{mL}$ were significant in cancer patients [53]. The relation of vancomycin MIC and mortality was also found in the non-cancer population [61, 65]. Notably, several studies have identified the association of inappropriate empirical antibiotic treatment with increased mortality among patients with MRSA BSIs $[20,62,63,66]$, and cancer patients were at an increased risk of receiving inappropriate therapy [62]. Appropriate initial antibiotic treatment should, therefore, gain adequate attention among patients with malignancy.

Several limitations of our study deserve consideration. First, all the included studies are observational, and there is a possibility of selection and observational bias. Second, the data are limited on BSIs solely in patients with solid malignancies as well as on BSIs from some geographic regions. Thus, we could not depict a more comprehensive picture of MRSA BSIs in cancer patients. Third, a direct comparison of the MRSA prevalence between cancer patients and general patients could not be achieved, which is precluded by the huge population of the latter group. Fourth, we did not find any study that provided incidence data after the search, so we could not predict the incidence trend. Fifth, a comparison between MRSA and MSSA was not made in our study, because we aimed to study MRSA which was a greater threat to life and the economy. Finally, the scarce information on predictor and mortality of MRSA bacteremia in cancer patients did not allow us to perform risk difference analysis and further establish decent prediction rules for MRSA development and mortality. Nevertheless, this study does provide relevant information on the prevalence, predictors, and mortality of bloodstream infections due to MRSA in the cancer population.

\section{Conclusions}

The global prevalence of MRSA BSIs among cancer patients is relatively low. However, methicillin resistance was detected in nearly half of $S$. aureus isolated in the blood of cancer patients. Moreover, the rates of MRSA BSIs in patients with malignancy did not decline over time as MRSA BSIs in the general hospital population and the high mortality rate was related to MRSA BSIs in cancer patients, suggesting the severity of MRSA bacteremia among cancer patients. As the current information concerning MRSA bacteremia among the population of cancer is still limited, especially with regard to risk factors associated with MRSA development and mortality. Further researches are warranted to explore the predictors and risk factors for mortality of MRSA bacteremia in the population of cancer, as well as more effective infection control measures to decrease the rate of MRSA bacteremia.

\section{Supplementary Information}

The online version contains supplementary material available at https://doi. org/10.1186/s12879-021-05763-y.

Additional file 1: Figure S1. Funnel plot

Additional file 2: Table S1. Quality assessment of included studies

Additional file 3: Table S2. Characteristics of studies included in the analysis of MRSA predictors and mortality

\section{Abbreviations}

MRSA: Methicillin-resistant Staphylococcus aureus; BSI: Bloodstream infection; SAB: S. aureus bacteremia; CI: Confidence interval; PRISMA: Preferred Reporting Items for Systematic Reviews and Meta-Analyses; WHO: World Health Organization; MSSA: Methicillin-susceptible S. aureus; CA-

MRSA: Community-associated methicillin-resistant Staphylococcus aureus

\section{Acknowledgements}

Not applicable.

\section{Authors' contributions \\ $\mathrm{ZL}$ and $\mathrm{HZ}$ wrote the main manuscript and fully participated in all analyses. YD and GW contributed to the study concept and design. GW and HW participated in literature search, data extraction, and quality assessment. All authors read and approved the final manuscript.}

\section{Funding}

The authors declare that they did not receive any funding from any source.

Availability of data and materials

The datasets used and/or analyzed during the current study are included in the manuscript. 


\section{Ethics approval and consent to participate}

Not applicable.

\section{Consent for publication}

Not applicable.

\section{Competing interests}

The authors declare that they have no competing interests.

\section{Author details}

'Department of Medical Oncology, The Second Affiliated Hospital, College of Medicine, Zhejiang University, Hangzhou, Zhejiang, China. ${ }^{2}$ Department of Infectious Diseases, Sir Run Run Shaw Hospital, College of Medicine, Zhejiang University, Hangzhou, Zhejiang, China. ${ }^{3}$ Department of Integrative Oncology, Cancer Hospital \& Shenzhen Hospital, Chinese Academy of Medical Sciences and Peking Union Medical College, Shenzhen, Guangdong, China.

Received: 2 July 2020 Accepted: 2 January 2021

Published online: 14 January 2021

\section{References}

1. Crawford J, Dale DC, Lyman GH, Crawford J, Dale DC, Lyman GH. Chemotherapy-induced neutropenia: risks, consequences, and new directions for its management. Cancer. (2004) 100(2):228-37. Cancer. 2004 100(9):1993-4.

2. Walshe LJ, Malak SF, Eagan J, Sepkowitz KA. Complication rates among Cancer patients with peripherally inserted central catheters. J Clin Oncol. 2002;20(15):3276-81.

3. Hsieh RW, Schrank GM, Hsu WT, Su KY, Lee CC. Temporal trend of microbiological profiles among patients with bloodstream infections: A comparison between cancer and noncancer patients in a nationwide database. J Clin Oncol. 2019;37.

4. Macedo F, Monteiro AR, Soares R, Pereira T, Bonito N, Sousa G. Bacteremia in oncologic patients and multi drug resistant microorganisms: A growing issue. Support Care Cancer. 2019;27(1):S139.

5. Islas-Munoz B, Volkow-Fernandez P, Ibanes-Gutierrez C, Villamar-Ramirez A, Vilar-Compte D, Cornejo-Juarez P. Bloodstream infections in cancer patients. Risk factors associated with mortality. Int J Infect Dis. 2018;71:59-64.

6. Thomer L, Schneewind O, Missiakas D. Pathogenesis of Staphylococcus aureus Bloodstream Infections. In: Abbas AK, Aster JC, Galli SJ, editors. Annu Rev Pathol, Vol 11. Annual Review of Pathology-Mechanisms of Disease. 2016;11. p. 343-364

7. McNicholas S, Talento AF, O'Gorman J, Hannan MM, Lynch M, Greene CM, et al. Cytokine responses to Staphylococcus aureus bloodstream infection differ between patient cohorts that have different clinical courses of infection. BMC Infect Dis. 2014;14:580.

8. $E J, J L, R H, P R, H$ H, R V , et al. Comparison of outcome and clinical characteristics of bacteremia caused by methicillin-resistant, penicillinresistant and penicillin-susceptible Staphylococcus aureus strains. Infect Dis (London, England). 2017:49(7):493-500.

9. Kobayashi D, Yokota K, Takahashi O, Arioka H, Fukui T, Wee CC. A prediction rule for mortality for inpatients with staphylococcus aureus bacteremia: A classification and regression tree (CART) analysis. J Gen Intern Med. 2013;28:S11.

10. Kim S-H, Park W-B, Lee K-D, Kang C-I, Kim H-B, M-d O, et al. Outcome of Staphylococcus aureus bacteremia in patients with eradicable foci versus noneradicable foci. Clin Infect Dis. 2003;37(6):794-9.

11. Ayau P, Bardossy AC, Sanchez G, Ortiz R, Moreno D, Hartman P, et al. Risk factors for 30-day mortality in patients with methicillin-resistant Staphylococcus aureus bloodstream infections. Int J Infect Dis. 2017;61:3-6.

12. Calderwood MS, Desjardins CA, Sakoulas G, Nicol R, Dubois A, Delaney ML, et al. Staphylococcal enterotoxin P predicts bacteremia in hospitalized patients colonized with methicillin-resistant staphylococcus aureus. J Infect Dis. 2014;209(4):571-7.

13. Kang $\mathrm{Cl}$, Song JH, Chung DR, Peck KR, Yeom JS, Son JS, et al. Bloodstream infections in adult patients with cancer: clinical features and pathogenic significance of Staphylococcus aureus bacteremia. Support Care Cancer. 2012;20(10):2371-8.

14. Cuervo SI, Cortés JA, Sánchez R, Rodríguez JY, Silva E, Tibavizco D, et al. Risk factors for mortality caused by Staphylococcus aureus bacteremia in cancer patients. Enferm Infecc Microbiol Clin. 2010;28(6):349-54.
15. Otto M. MRSA virulence and spread. Cell Microbiol. 2012;14(10):1513-21.

16. Vuong C, Yeh AJ, Cheung GY, Otto M. Investigational drugs to treat methicillin-resistant Staphylococcus aureus. Expert Opin Investig Drugs. 2016;25(1):73-93.

17. Bassetti M, Trecarichi EM, Mesini A, Spanu T, Giacobbe DR, Rossi M, et al. Risk factors and mortality of healthcare-associated and community-acquired Staphylococcus aureus bacteraemia. Clin Microbiol Infect. 2012;18(9):862-9.

18. Talon D, Woronoff-Lemsi MC, Limat S, Bertrand X, Chatillon M, Gil H, et al. The impact of resistance to methicillin in Staphylococcus aureus bacteremia on mortality. Eur J Intern Med. 2002;13(1):31-6.

19. Kang C-I, Song J-H, Chung DR, Peck KR, Ko KS, Yeom J-S, et al. Clinical impact of methicillin resistance on outcome of patients with Staphylococcus aureus infection: a stratified analysis according to underlying diseases and sites of infection in a large prospective cohort. J Inf Secur. 2010;61(4):299-306.

20. Paul M, Kariv G, Goldberg E, Raskin M, Shaked H, Hazzan R, et al. Importance of appropriate empirical antibiotic therapy for methicillin-resistant Staphylococcus aureus bacteraemia. J Antimicrob Chemother. 2010;65(12):2658-65.

21. $\mathrm{M} \mathrm{H}, \mathrm{L}$ M, S D. Bacteremia due to methicillin-resistant Staphylococcus aureus: new therapeutic approaches. Infect Dis Clin N Am. 2016;30(2):491-507.

22. Baden LR, Swaminathan $S$, Angarone M, Blouin G, Camins BC, Casper $C$, et al. Prevention and treatment of Cancer-related infections, version 2.2016, NCCN clinical practice guidelines in oncology. J Natl Compr Cancer Netw. 2016;14(7):882-913.

23. Moher D, Liberati A, Tetzlaff J, Altman DG. Preferred reporting items for systematic reviews and Meta-analyses: the PRISMA statement. J Clin Epidemiol. 2009;62(10):1006-12.

24. Alevizakos M, Gaitanidis A, Andreatos N, Arunachalam K, Flokas ME, Mylonakis E. Bloodstream infections due to extended-spectrum betalactamase-producing Enterobacteriaceae among patients with malignancy: a systematic review and meta-analysis. Int J Antimicrob Agents. 2017;50(5): 657-63.

25. Montassier E, Batard E, Gastinne T, Potel G, Cochetière MF. Recent changes in bacteremia in patients with cancer: a systematic review of epidemiology and antibiotic resistance. Eur J Clin Microbiol Infect Dis. 2013;32(7):841-50.

26. Wells GA, Shea B, O'Connell D, Peterson J, Welch V, Losos M, et al. The Newcastle-Ottawa Scale (NOS) for assessing the quality of nonrandomised studies in meta-analyses. Available from http://www.ohri.ca/programs/ clinical_epidemiology/oxford.asp. Accessed 11 Apr 2020.

27. DerSimonian R, Laird N. Meta-analysis in clinical trials. Control Clin Trials. 1986;7(3):177-88.

28. Barendregt JJ, Doi SA, Lee YY, Norman RE, Vos T. Meta-analysis of prevalence. J Epidemiol Community Health. 2013;67(11):974-8.

29. Huang CC, Wu CJ, Wang LR, Lee HC, Chang CM, Lee NY, et al. Antimicrobial susceptibility of bacteremic isolates from cancer patients with or without neutropenia at a medical center in southern Taiwan. J Microbiol Immunol Infect. 2011:44(5):376-81.

30. Lubwama M, Phipps W, Najjuka CF, Kajumbula H, Ddungu H, Kambugu JB, et al. Bacteremia in febrile cancer patients in Uganda. BMC Res Notes. 2019; 12(1):464.

31. Lai H-P, Hsueh P-R, Chen Y-C, Lee P-I, Lu C-Y, Lu M-Y, et al. Bacteremia in hematological and oncological children with febrile neutropenia: experience in a tertiary medical center in Taiwan. J Microbiol Immunol Infect. 2003;36(3):197-202.

32. Baskaran ND, Gan GG, Adeeba K, Sam IC. Bacteremia in patients with febrile neutropenia after chemotherapy at a university medical center in Malaysia. Int J Infect Dis. 2007;11(6):513-7.

33. Wang F-D, Lin M-L, Liu C-Y. Bacteremia in patients with hematological malignancies. Chemotherapy. 2005;51(2-3):147-53.

34. Miedema KGE, Winter RHLJ, Ammann RA, Droz S, Spanjaard L, de Bont ESJM, et al. Bacteria causing bacteremia in pediatric cancer patients presenting with febrile neutropenia-species distribution and susceptibility patterns. Support Care Cancer. 2013;21(9):2417-26.

35. Velasco E, Byington R, Martins CSA, Schirmet M, Dias LCM, Gonçalves VMSC. Bloodstream infection surveillance in a cancer Centre: a prospective look at clinical microbiology aspects. Clin Microbiol Infect. 2004;10(6):542-9.

36. Horasan ES, Ersoz G, Tombak A, Tiftik N, Kaya A. Bloodstream infections and mortality-related factors in febrile neutropenic cancer patients. Med Sci Monit. 2011;17(5):CR304-CR9.

37. Bhat G, Babu K, Lokanatha D, Lakshmaiah KC, Suresh Babu MC, Jacob L, et al. Bloodstream infections in febrile neutropenic patients at a tertiary 
cancer institute in South India: A timeline of clinical and microbial trends through the years. Indian J Med Paediatr Oncol. 2016;37(3):174.

38. Mvalo T, Eley B, Bamford C, Stanley C, Chagomerana M, Hendricks M, et al. Bloodstream infections in oncology patients at red cross war memorial Children's hospital, Cape Town, from 2012 to 2014. Int J Infect Dis. 2018;77:40-7.

39. Yamamoto M, Shiono $Y$, Suzuki I, Kouno K, Hiroshima $Y$, Kato $Y$, et al. Bloodstream infections in patients with hematological malignancies at the adult hematology ward of Yamagata University hospital. Yamagata Med J. 2010;28(2):39-49.

40. Gedik H, Simsek F, Kanturk A, Yildirmak T, Arica D, Aydin D, et al. Bloodstream infections in patients with hematological malignancies: which is more fatal - cancer or resistant pathogens? Ther Clin Risk Manag. 2014;10: $743-52$

41. Obeng-Nkrumah N, Labi AK, Acquah ME, Donkor ES. Bloodstream infections in patients with malignancies: implications for antibiotic treatment in a Ghanaian tertiary setting. BMC Res Notes. 2015;8:742.

42. Anatoliotaki M, Valatas V, Mantadakis E, Apostolakou H, Mavroudis D, Georgoulias V, et al. Bloodstream infections in patients with solid tumors: associated factors, microbial spectrum and outcome. Infection. 2004;32(2): 65-71.

43. El-Mahallawy H, Sidhom I, El-Din NHA, Zamzam M, El-Lamie MM. Clinical and microbiologic determinants of serious bloodstream infections in Egyptian pediatric cancer patients: A one-year study. Int J Infect Dis. 2005; 9(1):43-51.

44. Chen C-Y, Tien F-M, Sheng W-H, Huang S-Y, Yao M, Tang J-L, et al. Clinical and microbiological characteristics of bloodstream infections among patients with haematological malignancies with and without neutropenia at a medical Centre in northern Taiwan, 2008-2013. Int J Antimicrob Agents. 2017:49(3):272-81.

45. Kwon J-C, Kim S-H, Choi J-K, Cho S-Y, Park Y-J, Park SH, et al. Epidemiology and clinical features of bloodstream infections in hematology wards: one year experience at the Catholic blood and marrow transplantation center. Infect Chemother. 2013:45(1):51.

46. Kara Ö, Zarakolu P, Aşçioğlu S, Etgül S, Uz B, Büyükaşik Y, et al. Epidemiology and emerging resistance in bacterial bloodstream infections in patients with hematologic malignancies. Infect Dis (London, England). 2015;47(10):686-93.

47. Bodro M, Gudiol C, Garcia-Vidal C, Tubau F, Contra A, Boix L, et al. Epidemiology, antibiotic therapy and outcomes of bacteremia caused by drug-resistant ESKAPE pathogens in cancer patients. Support Care Cancer. 2014;22(3):603-10.

48. Schelenz S, Nwaka D, Hunter PR. Longitudinal surveillance of bacteraemia in haematology and oncology patients at a Uk cancer Centre and the impact of ciprofloxacin use on antimicrobial resistance. J Antimicrob Chemother. 2013;68(6):1431-8.

49. Arega B, Woldeamanuel Y, Adane K, Sherif AA, Asrat D. Microbial spectrum and drug-resistance profile of isolates causing bloodstream infections in febrile cancer patients at a referral hospital in Addis Ababa, Ethiopia. Infect Drug Resist. 2018;11:1511-9.

50. Greenberg D, Moser A, Yagupsky P, Peled N, Hofman Y, Kapelushnik J, et al. Microbiological spectrum and susceptibility patterns of pathogens causing bacteraemia in paediatric febrile neutropenic oncology patients: comparison between two consecutive time periods with use of different antibiotic treatment protocols. Int J Antimicrob Agents. 2005;25(6):469-73.

51. Srinivasan A, Seifried S, Zhu L, Srivastava DK, Flynn PM, Bankowski MJ, et al. Staphylococcus aureus bacteremia in pediatric patients with cancer. Pediatr Infect Dis J. 2010;29(2):172-4.

52. Bello-Chavolla OY, Bahena-Lopez JP, Garciadiego-Fosass P, Volkow P, GarciaHorton A, Velazquez-Acosta C, et al. Bloodstream infection caused by $S$. aureus in patients with cancer: a 10-year longitudinal single-center study. Support Care Cancer. 2018;26(12):4057-65.

53. Mahajan SN, Shah JN, Hachem R, Tverdek F, Adachi JA, Mulanovich V, et al. Characteristics and outcomes of methicillin-resistant staphylococcus aureus bloodstream infections in patients with cancer treated with vancomycin: 9year experience at a comprehensive cancer center. Oncologist. 2012;17(10): 1329-36.

54. Marín M, Gudiol C, Garcia-Vidal C, Ardanuy C, Carratalà J. Bloodstream infections in patients with solid tumors: epidemiology, antibiotic therapy, and outcomes in 528 episodes in a single cancer center. Medicine (United States). 2014;93(3):143-9.
55. EJ B. There should be no ESKAPE for febrile neutropenic cancer patients: the dearth of effective antibacterial drugs threatens anticancer efficacy. J Antimicrob Chemother. 2013;68(3):492-5.

56. Freifeld AG, Bow EJ, Sepkowitz KA, Boeckh MJ, Ito Jl, Mullen CA, et al. Clinical practice guideline for the use of antimicrobial agents in neutropenic patients with cancer: 2010 update by the infectious diseases society of america. Clin Infect Dis. 2011;52(4):e56-93.

57. Kourtis AP, Hatfield K, Baggs J, Mu Y, See I, Epson E, et al. Vital signs: epidemiology and recent trends in methicillin-resistant and in methicillinsusceptible Staphylococcus aureus bloodstream infections - United States. MMWR Morb Mortal Wkly Rep. 2019;68(9):214-9.

58. K H, DR C. Changing epidemiology of community-associated methicillinresistant Staphylococcus aureus in the Asia-Pacific region. Expert Rev AntiInfect Ther. 2016;14(11):1007-22.

59. Tumbarello M, de Gaetano DK, Tacconelli E, Citton R, Spanu T, Leone F, et al. Risk factors and predictors of mortality of methicillin-resistant Staphylococcus aureus (MRSA) bacteraemia in HIV-infected patients. J Antimicrob Chemother. 2002;50(3):375-82.

60. Wi YM, Rhee JY, Kang Cl, Chung DR, Song JH, Peck KR. Clinical predictors of methicillin-resistance and their impact on mortality associated with Staphylococcus aureus bacteraemia. Epidemiol Infect. 2018;146(10):1326-36.

61. Wang JT, Wang JL, Fang CT, Chie WC, Lai MS, Lauderdale TL, et al. Risk factors for mortality of nosocomial methicillin-resistant Staphylococcus aureus (MRSA) bloodstream infection: with investigation of the potential role of community-associated MRSA strains. J Inf Secur. 2010;61(6):449-57.

62. Rodríguez-Baño J, Millán AB, Domínguez MA, Borraz C, González MP, Almirante $B$, et al. Impact of inappropriate empirical therapy for sepsis due to health care-associated methicillin-resistant Staphylococcus aureus. J Inf Secur. 2009;58(2):131-7.

63. $\mathrm{O} G, M C, M A D, B P, V P, B$ A, et al. Predictive factors for early mortality among patients with methicillin-resistant Staphylococcus aureus bacteraemia. J Antimicrob Chemother. 2013;68(6):1423-30.

64. Ghanem GA, Boktour M, Warneke C, Pham-Williams T, Kassis C, Bahna P, et al. Catheter-related Staphylococcus aureus bacteremia in cancer patients - high rate of complications with therapeutic implications. Medicine. 2007; 86(1):54-60.

65. Wi YM, Kim JM, Joo EJ, Ha YE, Kang Cl, Ko KS, et al. High vancomycin minimum inhibitory concentration is a predictor of mortality in meticillinresistant Staphylococcus aureus bacteraemia. Int J Antimicrob Agents. 2012; 40(2):108-13.

66. $\mathrm{O} G, \mathrm{M} C, \mathrm{MA} D, \mathrm{~B} P, \vee \mathrm{P}, \mathrm{B}$ A, et al. Predictive factors for mortality in patients with methicillin-resistant Staphylococcus aureus bloodstream infection: impact on outcome of host, microorganism and therapy. Clin Microbiol Infect. 2013;19(11):1049-57.

\section{Publisher's Note}

Springer Nature remains neutral with regard to jurisdictional claims in published maps and institutional affiliations.

\section{Ready to submit your research? Choose BMC and benefit from:}

- fast, convenient online submission

- thorough peer review by experienced researchers in your field

- rapid publication on acceptance

- support for research data, including large and complex data types

- gold Open Access which fosters wider collaboration and increased citations

- maximum visibility for your research: over $100 \mathrm{M}$ website views per year

At $\mathrm{BMC}$, research is always in progress.

Learn more biomedcentral.com/submission 